\title{
Adoption pathway analysis: Representing the dynamics and diversity of adoption for agricultural practices
}

\author{
Oscar Montes de Oca Munguiaa, ${ }^{\mathrm{a}, *}$, , David J. Pannell ${ }^{\mathrm{a}}$, Rick Llewellyn ${ }^{\mathrm{a}, \mathrm{c}}$, Philip \\ Stahlmann-Brown ${ }^{\mathrm{d}}$. \\ aSchool of Agricultural and Environment, The University of Western Australia, \\ Crawley WA 6009 \\ bSCION Research, Wellington, New Zealand \\ ${ }^{\mathrm{C} C S I R O}$, Glen Osmond SA 5064 \\ dManaaki Whenua, Landcare Research, Wellington, New Zealand \\ *Email address: oscar.montes@scionresearch.com
}

\section{Abstract}

\section{CONTEXT}

Scholars have argued that empirical studies of adoption in agriculture should consider adoption as a dynamic process rather than a binary choice, but many empirical studies continue to be based on cross-sectional surveys in which adoption is treated binarily. In general, surveys put more emphasis on investigating adoption drivers (i.e. independent variables) at the expense of defining complete adoption measures (i.e. dependent variables).

\section{OBJECTIVE}

In this study, we present, demonstrate and illustrate a method - adoption pathways analysis - as an approach to better represent and analyse the dynamics and diversity of adoption.

\section{METHODS}

The approach consists of conducting a survey to define individual decisions at different stages of adoption and producing proportional flow diagrams representing the collective results of adopters moving through these various stages. The method is illustrated for four well-established practices in New Zealand pastoral farming using responses from 138 farmer surveys.

\section{RESULTS AND CONCLUSIONS}

Findings show how the current use status for each practice was the result of individual adoption journeys, converging in distinct pathways. For example, the current population of farmers can be broken down into those who have maintained or increased use of a practice over the medium or long term, those who have decreased their use of the practice since first adopting it, those who are still trialling the practice, those who adopted and then dis-adopted the practice, those who are aware of the practice but have never adopted it, and those who are not aware of it. The pathway to adoption may or may not have included trialling of the practice. Anticipating future pathways, we identified that farmers may intend to increase, maintain or decrease their adoption, and that current non-adopters may or may not be interested in future adoption. For different practices, different proportions of the farm population followed different adoption pathways. Observing these differences provides insights into adoption, and adoption barriers, for each practice. 


\section{SIGNIFICANCE}

Our approach provides a method for adoption research with a highly informative way to unpack the diversity of dynamic adoption pathways for agricultural practices, addressing the current imbalance in survey design that puts more emphasis on potential drivers of adoption at the expense of adoption measures. We discuss the potential uses of adoption pathways analysis to agricultural researchers and extension agents, and its potential to contribute to better explaining past adoption or predicting future adoption.

\section{Key words}

Adoption dynamics, agricultural adoption and diffusion, pathways analysis, technological change

\section{Introduction}

Scholars have argued that empirical studies of adoption in agriculture should consider adoption as a dynamic process rather than a binary choice (Feder et al. 1985; Pannell et al. 2006; Leeuwis \& Aarts 2011; Vanclay et al. 2013; Andersson \& D’Souza 2014; Pannell \& Claassen 2020; Weersink \& Fulton 2020). However, empirical studies often still simplify adoption measures to a binary variable. Wauters \& Mathijs (2014) and Zscheischler et al. (2014) noted that because adoption is highly context-specific and dynamic in nature, it lacks consistency in the definition of variables and measures required for quantitative systematic reviews in the fields of agricultural adoption. To that end, Wilkinson (2011) lists reasons why agricultural adoption is hard to define:

- Adoption is a dynamic process, not steady state or binary

- Adoption is often incomplete or partial, across populations of adopters and geography and within a farm

- Adoption is gradual - making it difficult to distinguish it from trialling

- Components of technological packages are often adopted in a stepwise manner

- Innovations are often used in flexible ways and keep changing over time, adapting to the individual context

- Innovations might be dis-adopted at any time, as part of an 'innovation cycle'.

Despite these difficulties, researchers have proposed clear stages in the adoption process that can be used to define consistent measures that better reflect agricultural adoption. A staged model of adoption at a farm level consisting of 6 stages was outlined in Pannell et al. (2006): awareness, non-trial evaluation, trial evaluation, adoption, review and modification and disadoption. More recently, Brown et al. (2017) and Pannell \& Claassen (2020) suggested more 
nuanced stages applicable to the review and modification stage: full adoption, partial adoption, alternating adoption, and opportunistic adoption. This is important because Brown et al. (2017) showed that defining adoption as a binary decision can result in overestimating the economic and environmental benefits of adoption. Brown et al. (2017) explained that achieving Conservation Agriculture (CA) environmental outcomes in Africa relies on a sustained and intensive deployment of different combinations of practices. The authors not only found a multitude of working definitions of CA, but also that there were several points in time that could be used to measure 'adoption' for each practice or combination of practices. This point in time could be the start of trialling CA in one plot of land, when the trial is selffunded rather than subsidised, or when the farmer decides to expand the trial.

Adoption researchers also need to consider the dynamics between adopters, technologies and their context. An early study by Mason (1962) concluded that: "It would seem that there is no single adoption process for all practices" (p. 111). A number of systematic reviews of agricultural adoption, including Knowler \& Bradshaw (2007), Baumgart-Getz et al. (2012), Tey \& Brindal (2012), Wauters \& Mathijs (2014), and Liu et al. (2018), support this finding by not being able to produce a consistent explanation of why farmers choose to adopt or not adopt new technologies and practices (Montes de Oca Munguia \& Llewellyn 2020; Pannell \& Claassen 2020). As a result, some scholars have explicitly rejected adoption frameworks to analyse technological change and innovation systems (Glover et al. 2016, 2019; Hermans et al. 2020), while, at the same time, acknowledging that adoption and diffusion are pragmatic measures of the individual and collective benefits of innovation systems. This is especially relevant in regards to understanding and measuring the impact of research and extension activities in agricultural innovation systems (Douthwaite et al. 2003; Eastwood et al. 2017; Wigboldus et al. 2016), and understating adoption at multiple levels, geographical scales and contexts (Hermans et al. 2020; Kuntosch \& König 2018; Prokopy et al. 2019).

Several analytical methods have been suggested to address the dynamics and complexity of technological change. Jabbar et al. (1998) defined a conceptual model for "adoption pathways" in which they measured the time-lags of potential adopters moving from the moment of awareness to continuous use. The stages they considered were: knowledge (i.e. learning), adoption and use patterns (i.e. discontinuous use, continuous use). Springer-Heinze et al. (2003) proposed "impact pathways analysis" to reflect upon the process of agricultural innovation, mainly involving interviewing participants. Douthwaite et al. (2003) proposed "impact pathway evaluation" to account for the complexity in technology adoption in economic evaluation methods, and more recently, Stringer et al. (2020) proposed "adaptation 
and development pathways". Using farmer typologies, they illustrated how all farmers start at different adoption stages, and follow different pathways towards the same outcome of sustainable practice. They then suggest interventions to encourage farmers to follow preferred pathways.

How, then, can adoption be measured in a pragmatic way that is compatible with these analytical frameworks? It is clear that such measures need to capture the dynamics and fluidity of adoption through the adoption process (Eastwood et al., 2017; Glover et al., 2019; Hermans et al., 2020; Kuehne et al., 2017), capturing both individual and collective adoption and offering the ability to differentiate adoption patterns for distinct groups of individuals (Boru Douthwaite et al. 2003; Jabbar et al. 1998; Prokopy et al. 2019; Stringer et al. 2020), types of technologies (B. Douthwaite et al. 2001; Sartas et al. 2020) and their context (Kuntosch \& König 2018; Wigboldus et al. 2016).

In empirical studies of innovation systems or technological change, practitioners inevitably have to ask farmers about adoption. Responses are typically collected through cross-sectional surveys, sometimes followed by more intensive qualitative methods such as interviews. Responses are then normally used to define numerical models (e.g. statistical regression). In our observation, more emphasis is given to the definition of the reasons for adoption (i.e. explanatory variables) than to the dependent variables (i.e. adoption measures). In many cases, this results in truncated, binary or partial measures of the adoption process.

In this study, we propose "adoption pathways analysis" as an approach to better understand the dynamics and diversity of adoption. The method consists of establishing individual farmers' adoption journeys for different innovations and a visual analysis to represent the collective pathways using a simple cross-sectional survey. Using four well-established practices in New Zealand pastoral farming as case studies, we tested this approach to illustrate and enable a more nuanced analysis of their adoption.

\subsection{Study area and practices}

Pastoral farming dominates the rural agribusiness sector in New Zealand, particularly sheep and beef cattle farming and dairy farming. Because technology plays an important role in the sector, we collaborated with two research and extension organisations ${ }^{1}$ to identify a range of technological practices to better understand adoption. The practices were:

\footnotetext{
${ }^{1}$ The Red Meat Profit Partnership (www.rmpp.co.nz) and DairyNZ (www.dairynz.co.nz)
} 
- Use of Body Condition Scoring (BCS). The assessment of BCS is used to estimate body fat reserves in both cows (visual) and ewes (feeling backbone with fingers and thumb). BCS is used as a management tool by pastoral farmers to determine livestock's feed requirements and improve reproductive performance.

- Use of pasture management software. Use of software and applications in computers, tablets and smartphones to calculate feed demand, feed availability and feed quality for sheep and cattle at different times of the year and for different levels of production. Information can be used for both tactical, operational and strategic decisions.

- Use of Plantain and/or Lucerne for summer grazing. Plantain and Lucerne are used to increase the amount and quality of summer feed in grazing systems. Plantain is more often used as a pasture mix, but it can also be used as a special purpose crop; Lucerne is used on soils with low soil moisture-holding capacity to increase production vis-à-vis grass.

- Use of a formal, audited nutrient management plan. Used to manage nutrients (namely, nitrogen and phosphorous ) on the farm in a formal, audited way. Nutrient management plans can be developed in conjunction with a fertiliser or farm consultant or as part of an environmental plan developed by industry or local government. Nutrient management may include managing the type, placement and timing of fertiliser applications; crop rotations; precision application; and excluding stock from waterways.

The feasibility to trialling each of these practices varies, and each practice has a different indicator of continuous use and extent of use. For example, while it is relatively clear how the use of Plantain and Lucerne could be trialled on a limited basis, it is unclear how audited nutrient management plans could be trialled.

Another example to illustrate differences is continuous use. For Plantain and Lucerne, continuous use consists of integrating both species into the permanent yearly rotation grazing in the farm. Plantain is a short-term crop which typically lasts between 2 or 3 years and which requires a dedicated paddock in a permanent grazing rotation of 6 paddocks. In contrast, Lucerne is a perennial crop that can last more than 10 years in the right location and under good management. It also needs to be rotationally grazed, with a rotation of around 6 weeks. The use of Lucerne and Plantain contrast with the use of pasture management software, which could be routinely used both as a strategic tool for scenario planning (e.g. once a year) or as a tactical tool (e.g. weekly or daily).

A further example is extent of use, which would also be measured differently for each of the four practices. The use of Plantain and Lucerne and the use of pasture management software 
could be linked to a specific area of the farm, while BCS and audited nutrient management plans might not. Such relativity needs to be accounted for while designing adoption measures to ensure a valid comparison amongst practices.

\section{Methods}

Adoption pathways analysis consists of establishing individual adoption journeys through adoption process states, and graphically representing collective pathways to adoption.

\subsection{Establishing individual adoption journeys}

We designed a cross-sectional survey consisting of 7 questions to account for the nuances of the adoption process of different innovations (Pannell et al. 2006; Wilkinson 2011; Brown et al. 2017; Pannell \& Claassen 2020). Figure 1 shows a representation of the potential flows between the adoption stages outlined by Pannell et al. (2006). The first step in the survey design was to define questions to capture individual decisions at these different stages of adoption. In order to capture patterns of use (i.e. the review and modification stage), we included questions to determine current levels of use and relevant changes to those levels over time. Subsequently, we added questions to capture future intentions for both current users and non-users. The survey was piloted with a group of colleagues to ensure the questions' clarity and logic.

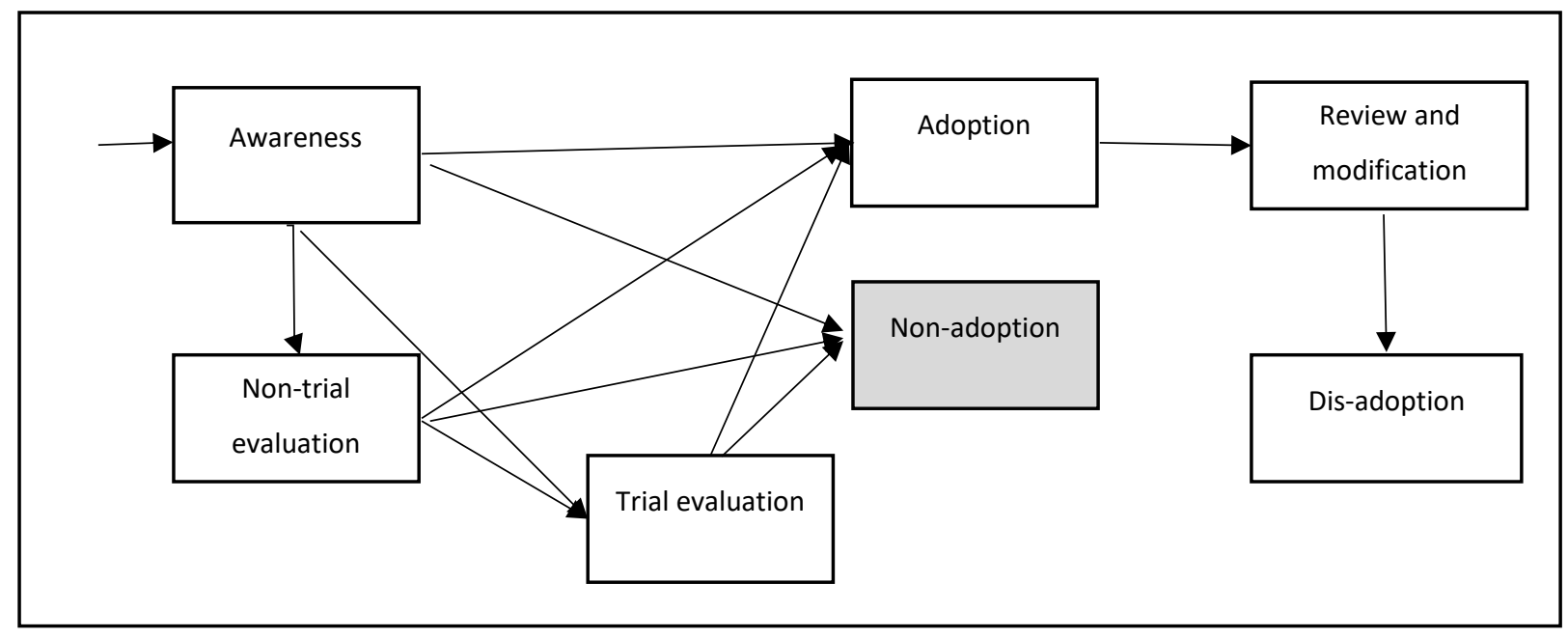

Figure 1. Representation of flows in the adoption process outlined by Pannell et al. (2006).

In Figure 1, the boxes represent different adoption states. Implicit in this process is the possibility that farmers may fail to proceed to a subsequent stage, stopping at one of the boxes, or even stopping prior to reaching awareness. 
Table 1 shows the 7 questions used to identify individual adoption journeys through adoption states, their dependencies and their potential answers. Question 1 was used to ascertain landowner's current adoption status. Answers to this question allowed us to identify nonadopters, former adopters and current adopters using the practice at different levels of intensity, assessed by the respondent. Question 2 was used to find out if respondents could identify a trial period for the innovation as part of their evaluation process. Question 3 was used to detect changes in the level of use from when adoption occurred until now. Questions 4 and 5 were used to establish a timeline from the time in which the respondent became aware of the innovation to the time of first use (either by trial or not), allowing us to calculate the time in which the adoption had been in use. Question 4 was also used to differentiate between two groups of non-adopters: those who are still not aware of the applicability of the innovation to their agribusiness and those who went through a non-trial evaluation period and decided not to adopt the practice. Question 6 was used to find out users' intention to change the current level of use in the near future, and question 7 was used to find out if nonadopters and former adopters were willing to re-consider adopting the practice.

Table 1. Questions to define measures of adoption for agricultural innovations.

\begin{tabular}{|c|c|}
\hline Question & Answers \\
\hline \multicolumn{2}{|c|}{$\begin{array}{l}\text { Trial and current use } \\
\end{array}$} \\
\hline $\begin{array}{l}1 \text { To what extent has INNOVATION A been } \\
\text { used in your business to this day? }\end{array}$ & $\begin{array}{l}\text { I have never used it (1) } \\
\text { I used it in the past, but not anymore (2) } \\
\text { I use it at the minimum extent possible } \\
\text { (3) } \\
\text { I use it moderately (4) } \\
\text { I use it at the maximum extent possible } \\
(5)\end{array}$ \\
\hline $\begin{array}{l}2 \text { Did you use INNOVATION A on a limited } \\
\text { basis in order to decide to use it further? }\end{array}$ & $\begin{array}{l}\text { Yes }(1) \\
\text { No }(2)\end{array}$ \\
\hline \multicolumn{2}{|c|}{ For those who answered 3,4 or 5 in question 1} \\
\hline $\begin{array}{l}3 \text { Have there been any changes in the level of } \\
\text { implementation since you adopted } \\
\text { INNOVATION A? }\end{array}$ & $\begin{array}{l}\text { Decrease in use since adopted (1) } \\
\text { No change in use since adopted (2) } \\
\text { Increase in use since adopted (3) }\end{array}$ \\
\hline \multicolumn{2}{|c|}{ Timelines } \\
\hline $\begin{array}{l}4 \text { Approximately when did you first become } \\
\text { aware of INNOVATION A being used in } \\
\text { your industry? }\end{array}$ & $\begin{array}{l}\text { I am not aware of INNOVATION A } \\
\text { being used in my industry (1) } \\
\text { Cannot remember (o) } \\
\text { Year }\end{array}$ \\
\hline \multicolumn{2}{|l|}{ For those who answer $2,3,4$ or 5 in question 1} \\
\hline $\begin{array}{l}5 \text { When did you start trialling or using } \\
\text { INNOVATION A as part of your operation? }\end{array}$ & $\begin{array}{l}\text { Cannot remember (o) } \\
\text { Year }\end{array}$ \\
\hline \multicolumn{2}{|c|}{ Future intentions } \\
\hline For those who answered 3,4 or 5 in question 1 & \\
\hline
\end{tabular}




\begin{tabular}{|l|l|}
\hline $\begin{array}{l}\text { 6 Do you intend to make any changes to the } \\
\text { current level of use of INNOVATION A in } \\
\text { the near future? }\end{array}$ & $\begin{array}{l}\text { Yes, I'm considering decreasing its use } \\
\text { in the future (1) } \\
\text { No, I plan to keep it as is (2) } \\
\text { Yes, I'm considering intensifying its use } \\
(3) \\
\text { Not sure (4) }\end{array}$ \\
\hline \begin{tabular}{l|l} 
For those who answered 1 or 2 in question 1 \\
\hline $\begin{array}{l}\text { 7 Would you consider using INNOVATION } \\
\text { A in the near future? }\end{array}$
\end{tabular} & $\begin{array}{l}\text { Yes (1) } \\
\text { Maybe (2) } \\
\text { No (3) }\end{array}$ \\
\hline
\end{tabular}

We provided respondents with a description of each practice as defined in section 1.2 to answer the questions presented in Table 1 . The questions were thus designed to be generic to be applicable to the four practices.

\subsubsection{Survey application}

The Survey of Rural Decision Makers (SRDM) is conducted biennially by Manaaki Whenua Landcare Research, a government-owned research institute in New Zealand. The SRDM is a large, voluntary Internet-based survey of farmers, foresters, and growers (Stahlmann-Brown, 2019); the survey follows ethics processes established by the New Zealand Association of Social Science Research. The vast majority of respondents to the SRDM consent to participating in additional, more targeted surveys. This study relied on one of these additional surveys, targeting technological adoption among New Zealand pastoralist farmers in 2018. As with all surveys, participation is voluntary, and hence the sample is self-selected. The survey was open for three weeks, and a reminder was sent to potential respondents one week before the survey closure. A total of 152 responses were collected from the 411 invitations sent out originally, yielding a response rate of $37 \%$. Surveys took an average of 15 minutes to complete. Among all submitted surveys, 138 were complete. These complete responses form the basis of our study. In order to increase the likelihood of survey completion by reducing the length of the survey, each respondent was asked to answer the questions relating to only two practices. Randomly allocated, half of respondents answered questions regarding the use of body condition scoring (69 complete responses) and the use of pasture management software (67 complete responses), while the other half answered questions regarding the use of Plantain and Lucerne (69 complete responses) and the use of audited nutrient management plans (68 complete responses).

Based on the questionnaire responses shown in Table 1, we defined 7 current adoption states consisting of 4 categories of current users and 3 categories of current non-users (Table 2). 
Table 2. Definition of a full set of adoption states for adoption pathway analysis.

\begin{tabular}{|c|c|c|c|}
\hline \multicolumn{2}{|c|}{ Adoption status } & Description & Definition \\
\hline \multirow{3}{*}{ 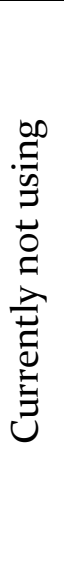 } & Not aware & $\begin{array}{l}\text { Landowner was not aware } \\
\text { of the applicability of the } \\
\text { innovation to their } \\
\text { agribusiness. }\end{array}$ & $\begin{array}{l}\text { Landowners were identified in this } \\
\text { category if they answered "I am not } \\
\text { aware of INNOVATION A being } \\
\text { used in my industry" in question } 4 .\end{array}$ \\
\hline & $\begin{array}{l}\text { Never } \\
\text { adopted }\end{array}$ & $\begin{array}{l}\text { Landowner went through } \\
\text { a non-trial evaluation } \\
\text { period and decided not to } \\
\text { adopt the innovation. }\end{array}$ & $\begin{array}{l}\text { Landowners were identified in this } \\
\text { category if they were aware of the } \\
\text { practice but answered "I have never } \\
\text { used it" in question } 1 .\end{array}$ \\
\hline & $\begin{array}{l}\text { Dis- } \\
\text { adopted }\end{array}$ & $\begin{array}{l}\text { Landowner used the } \\
\text { innovation in the past but } \\
\text { decided to stop using it. }\end{array}$ & $\begin{array}{l}\text { Landowners were identified in this } \\
\text { category if they answered "I used it } \\
\text { in the past, but not anymore" in } \\
\text { question } 1 \text {. }\end{array}$ \\
\hline \multirow{4}{*}{ 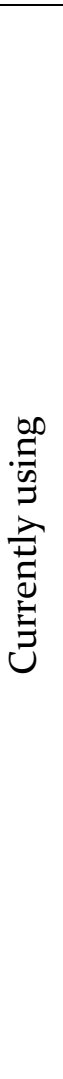 } & Trialling* & $\begin{array}{l}\text { Landowner is currently } \\
\text { using the practice as a } \\
\text { trial. }\end{array}$ & $\begin{array}{l}\text { Landowners were identified in this } \\
\text { category if they answered yes to } \\
\text { question } 2 \text { and have been using the } \\
\text { innovation for no more than } 3 \text { years } \\
\text { at the time of the survey. }\end{array}$ \\
\hline & $\begin{array}{l}\text { Decreased } \\
\text { use since } \\
\text { adoption }\end{array}$ & $\begin{array}{l}\text { Landowner is a current } \\
\text { user, but it has decreased } \\
\text { the use of the innovation } \\
\text { since adoption. }\end{array}$ & $\begin{array}{l}\text { Landowners were identified in this } \\
\text { category if they answered "Decrease } \\
\text { in use since adopted" in question } 3 .\end{array}$ \\
\hline & $\begin{array}{l}\text { Constant } \\
\text { or } \\
\text { increased } \\
\text { use for up } \\
\text { to } 5 \\
\text { years* }\end{array}$ & $\begin{array}{l}\text { Landowner has been } \\
\text { using the innovation for } \\
\text { up to } 5 \text { years, either } \\
\text { steadily or increasing it } \\
\text { use since adoption. }\end{array}$ & $\begin{array}{l}\text { Landowners were identified in this } \\
\text { category if they answered "No } \\
\text { change in use since adopted" or } \\
\text { "Increase in use since adopted" in } \\
\text { question } 3 \text { and have been using the } \\
\text { innovation for up to } 5 \text { years at the } \\
\text { time of the survey. }\end{array}$ \\
\hline & $\begin{array}{l}\text { Constant } \\
\text { or } \\
\text { increased } \\
\text { use for } \\
\text { more } \\
\text { than } 5 \\
\text { years* }\end{array}$ & $\begin{array}{l}\text { Landowner has been } \\
\text { using the innovation for } \\
\text { more than } 5 \text { years, either } \\
\text { steadily or increasing it } \\
\text { use since adoption. }\end{array}$ & $\begin{array}{l}\text { Landowners were identified in this } \\
\text { category if they answered "No } \\
\text { change in use since adopted" or } \\
\text { "Increase in use since adopted" in } \\
\text { question } 3 \text { and have been using the } \\
\text { innovation for more than } 5 \text { years at } \\
\text { the time of the survey. }\end{array}$ \\
\hline
\end{tabular}

* The 3-year threshold for trialling and the 5-year threshold for length of use were chosen for all practices for simplicity. We considered these time periods were appropriate to consider the full rotation of a Plantain crop ( 2 to 3 years) and because nutrient management plans are a relatively recent practice, and we considered that very few farmers would have been using them for a long period of time.

\subsection{Representing collective adoption pathways}

We used Sankey diagrams (Bogart 2020) to represent and visualise adoption as a proportional flow of adopters moving from one stage of the adoption process to the next for each innovation. Table 3 shows the colours used in the adoption pathway diagrams presented in the results section. In the middle of the table, ranging from deep red to dark green, are 
landowners' current adoption states. To the left, different shades of blue represent the adoption steps taken to the current states (i.e. awareness, evaluation and first adoption), and to the right, different shades of cyan represent future intentions of current users while different shades of grey represent levels of adoption interest amongst current non-adopters.

Table 3 Colours used to represent adoption pathways for each practice.

\begin{tabular}{|c|c|c|}
\hline Past & Present & Future \\
\hline Aware & Constant or increased use for more than 5 years & Intention to increase use \\
\hline $\begin{array}{l}\text { Started using } \\
\text { without trial }\end{array}$ & Constant or increased use for up to 5 years & $\begin{array}{l}\text { Intention to remain at } \\
\text { current level }\end{array}$ \\
\hline \multirow[t]{5}{*}{$\begin{array}{l}\text { Started using } \\
\text { with trial }\end{array}$} & Decreased use since adoption & Intention to decrease use \\
\hline & Trialling & \\
\hline & Dis-adopted & Interested in adoption \\
\hline & Never adopted & $\begin{array}{l}\text { May be interested in } \\
\text { adoption }\end{array}$ \\
\hline & Not aware & Not interested in adoption \\
\hline
\end{tabular}

\section{Results}

The aim of this section is to illustrate the application of adoption pathways analysis. Thus, for brevity, we describe the results of the analysis for one practice in this section and present the description of the results for the remaining practices in Appendix 1. The results presented in this study are not intended to be representative of the sector.

\subsection{Adoption pathways}

Figure 2 shows the pattern of adoption for BSC from when the practice became available to farmers to its current level of uptake and use. The placing of the vertical lines in the diagram are for illustrative purposes and are not at scale, but they do indicate different time spans for each stage based on survey responses (e.g. the difference between time from awareness to start using the practice with or without trial). The numerical values for these differences are described in the text explaining the figure. The number following each label in the diagram is the number of respondents following each path, these numbers are also presented as a percentage of total responses. 


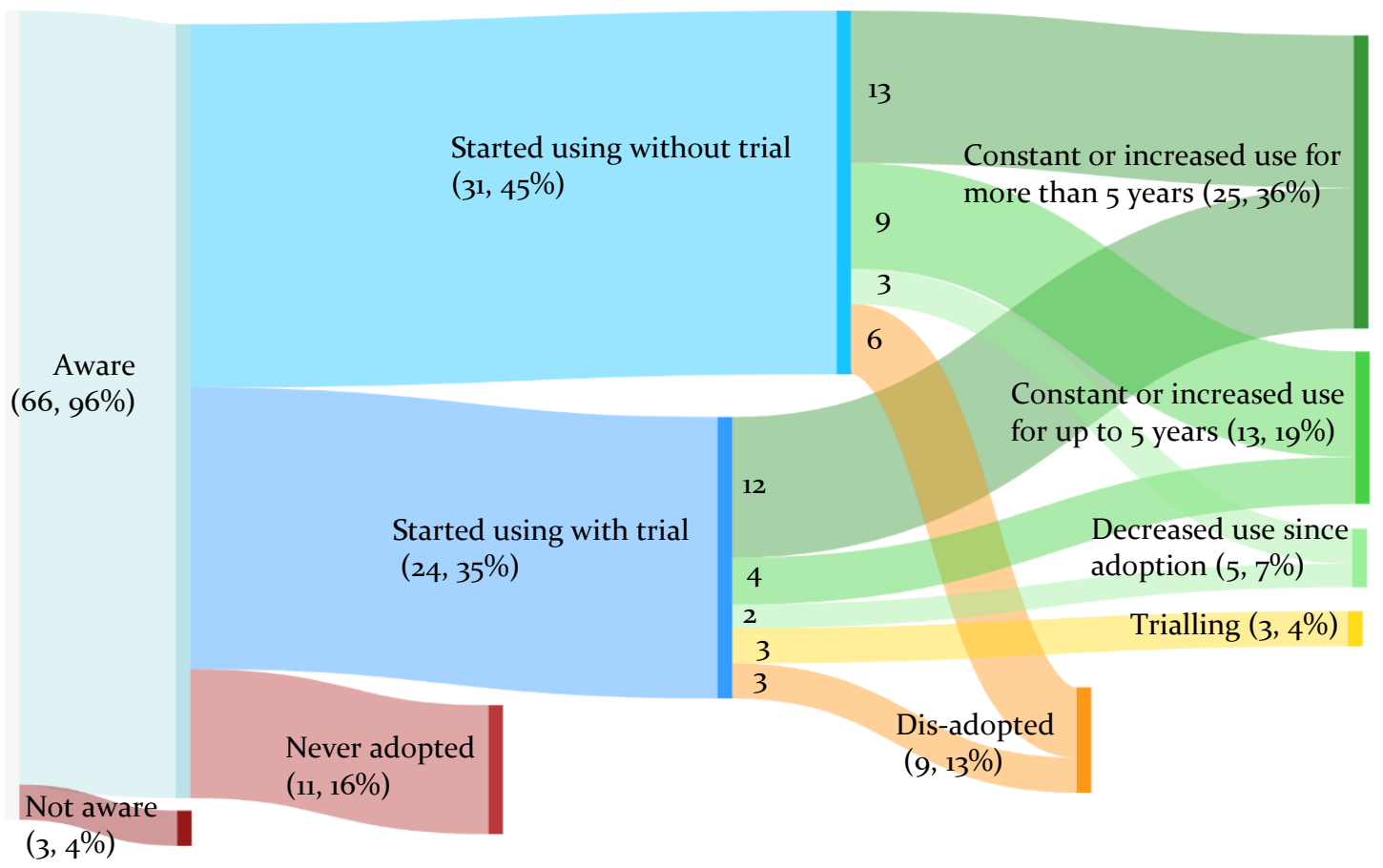

Figure 2 Adoption pathway for the use of body condition scoring amongst pastoral farmers in New Zealand.

The diagram illustrates the time from awareness (left-had side) to current use (right hand side). The placing of the vertical lines illustrate different time spans for each stage based on survey responses (e.g. the difference between time from awareness to start using the practice

with or without trial), but they are not at scale. The number following each label is the number of respondents following each path, these numbers are also presented as a percentage of total responses).

Figure 2 shows that virtually all respondents were aware of the use of body condition scoring as an available practice for their operation (indeed we observed that all practices were well known). Survey results indicated that farmers that adopted BCS after identifying a trial period adopted faster than those who didn't ( 2.2 years). The average timespan from awareness to the time of the survey was 16 years. This practice had the longest time span among the 4 practices. If the adoption of BCS was measured binarily (i.e. the time of first use), the adoption rate would be estimated at $80 \%$. However, the diagram shows that when former adopters are excluded from this calculation, the level of adoption at the time of the survey was $67 \%$. Moreover, if the benefits of adopting BSC were to be calculated by its level of use and/or sustained use over a period of time, the diagram shows that long-term users of BCS account for $36 \%$ of current users while $19 \%$ of current users have been consistently using it for up to 5 years at the time of the survey, $5 \%$ of current users have reported a decrease use of the practice and $4 \%$ are still trialling it. 
Figure 3 illustrates the differences between the adoption pathways for the four practices.

Detailed results for pasture management software, Plantain/Lucerne and nutrient management plans are presented in Appendix 1.
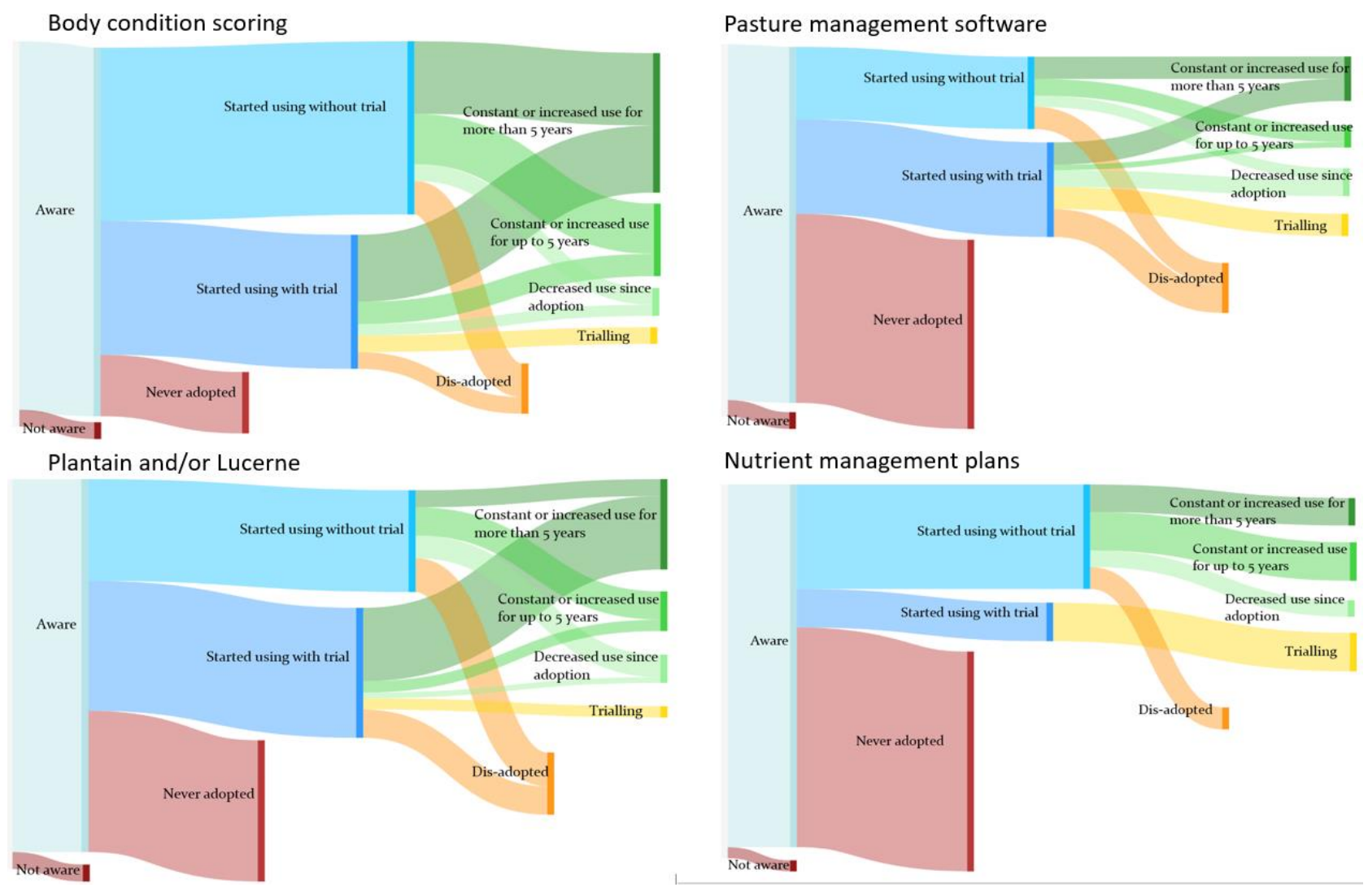

Figure 3. Adoption pathways of four pastoral practices in New Zealand.

Figure 3 suggests that farmers followed different pathways to reach their current adoption states for each practice. For example, both BCS and Plantain/Lucerne had a relatively large number of long-term users in relation to the other two practices, but while the vast majority of long-term users of Plantain/Lucerne trialled the practice first, less than half of long-term users of BCS did.

\subsection{Future pathways}

Figure 4 shows the current status for BCS at the time of the survey and the future intentions of landowners, including intended changes in levels of use by current users and the reported level of interest in BCS amongst non-adopters and former adopters. 


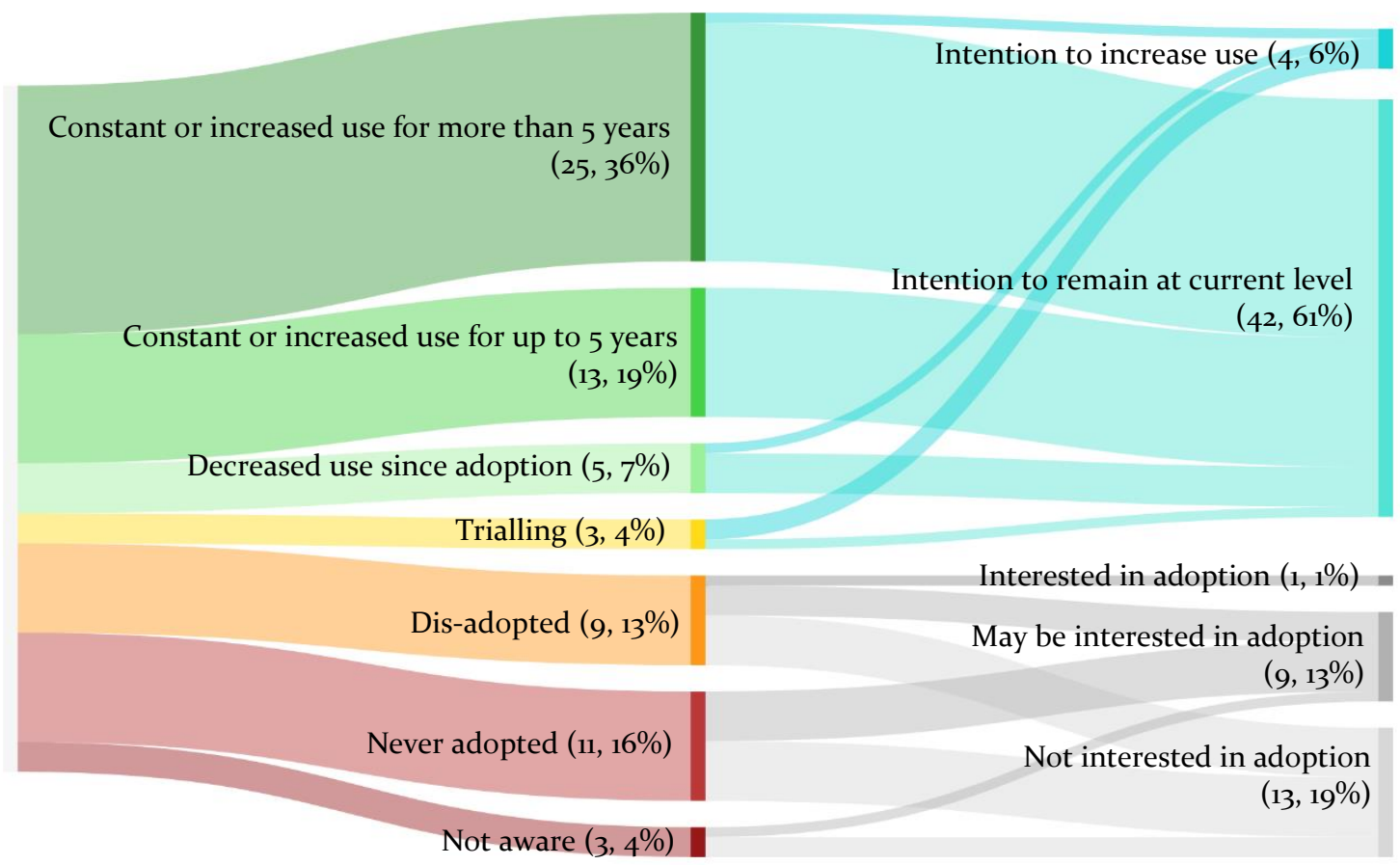

Figure 4 Future pathway for the use of body condition scoring amongst pastoral farmers in New Zealand.

Figure 4 shows that the vast majority of current users of BCS intended to continue using the practice at the same extent, with only a minority of current users indicating an intention to increase its use in the near future. Those are landowners currently trialling the practice; one surveyed landowner has been decreasing its use over time. Figure 4 also shows that the majority of non-adopters and former adopters were not interested in adopting BCS. However, a number from each category of non-adopters indicated some interest.

Figure 5 shows the differences between future adoption pathways for the four practices.

Detailed results for pasture management software, Plantain/Lucerne and nutrient management plans are presented in Appendix 1 

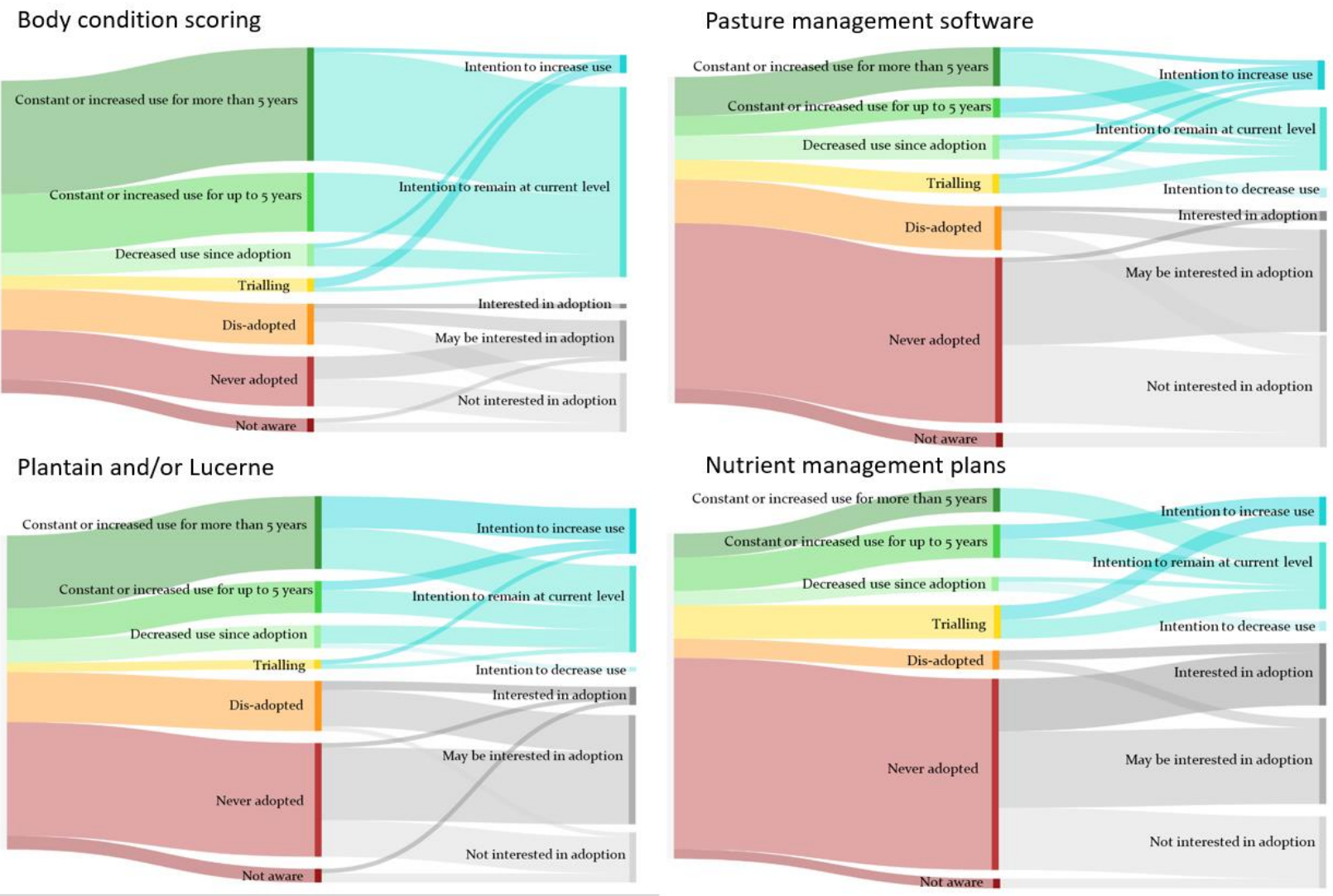

Figure 5. Future adoption pathways of four pastoral practices in New Zealand.

Figure 5 shows the diversity of farmers' future intentions for each practice, whether they are current users or non-users. For example, Figure 5 shows that the use of pasture management software and the use of nutrient management plans had the lowest level of adoption and current use in relation to the other practices. However, nutrient management plans clearly showed a high level of interest by those farmers that haven't adopted yet, suggesting that some farmers were 'sitting on the fence' regarding this practice.

\section{Discussion}

This study demonstrates the ability of adoption pathways analysis to establish individual farmers' adoption journeys and to represent the collective pathways followed by these individuals. This approach facilitates comparing collective pathways across practices by analysing both historical flows and future intentions. Adoption pathways analysis thus provides better measures of adoption and analytical flexibility to those practitioners analysing technological change and innovation systems that have expressed reservations about using adoption frameworks (Glover et al. 2016, 2019; Hermans et al. 2020).

Our diagrams illustrate how current use status for each practice was the result of a numerous pathways in which trialling takes centre stage. Our results show that some practices were 
adopted earlier if they were trialled, although that was not always the case. Adopting without a trial seemed to increase the chance of dis-adoption, but again, that was not always the case. While trialling was determined in our study as initially using an innovation on a limited basis in order to decide whether to use it further, it needs to be recognised that ambiguity remains around the specification of trialling. This is not unexpected given the diverse forms of trialling required for different innovations and likely differences in what is required to adequately trial a new innovation. The nature of trialling has implications for the nature and timing of any subsequent adoption and expanded use. For example, to trial and evaluate just one full rotation of the crop Plantain or longevity of Lucerne under grazing could require at least 3 years, and the area required for realistic trialling under grazing can be substantial (Douthwaite et al. 2001; Roesch-Mcnally et al. 2018). In other cases, a short-term evaluation of establishment and initial growth may be considered a trial period, meaning that a decision to adopt will always require expansion of use. Trialling is not only an important component of diverse adoption pathways (Wigboldus et al. 2016), but considering potential diversity of trialling is likely to be important when evaluating adoption pathways.

Adoption pathways analysis may be used to complement other analytical methods used in the field to address the dynamics and complexity of technological change. For example, proportional flow diagrams could help illustrate the adoption pathways approach used by Jabbar et al. (1998). Individual adoption journeys could also be used to identify individuals whose decisions could be further analysed to identify elements influencing desirable pathways (Stringer et al. 2020) and to reflect upon journeys through the process of innovation (SpringerHeinze et al. 2003).

As a research tool for extension planning or policy formulation, adoption pathway analysis may also be used to develop more effective strategies for engaging with the farming population, or sub-populations of it. For instance, researchers can identify and engage with groups of farmers following certain trajectories (such as those farmers that have decreased the use of a practice and intend to further decrease it - signalling potential dis-adoption) and contrast those with farmers who have increased the use of the same practice and who intend to further increase it. As such, adoption pathways analysis can be used as a tool to assist in the understanding and measuring the impact of research and extension activities in agricultural innovation systems (Douthwaite et al. 2003; Eastwood et al. 2017; Wigboldus et al. 2016) by providing measures that can be used in adaptive management (Douthwaite et al. 2003) or by supplementing the "timeline analysis methodology" (Eastwood et al. 2017) to estimate the impact of specific research interventions. For example, if applied at different times during a 
research project, adoption pathways analysis can detect changes in past trends and future intentions.

Adoption researchers and modellers may also use this approach to better understand the patterns of adoption of potential adopters for different types of technologies, and such knowledge could be used to identify analogues that could inform the uptake of a new technology by that particular target population (see Green \& Armstrong 2007 and Goodwin et al. 2014), or to complement existing methods to reflect the unique characteristics and context of the target population for scaling efforts (Sartas et al. 2020; Wigboldus et al. 2016). To this effect, adoption pathways analysis can be applied to a large number of adoption examples with the aim of identifying patterns for different types of farmers or different types of technologies. For example, do farmers in a particular agricultural industry (e.g. wheat farmers, pastoral farmers) follow a characteristic pattern with adoption pathways? Our approach can be helpful in predicting how cohorts of people move through the various adoption pathways.

Further research using this approach can also lead to a systematic way of classifying farmers and innovations to investigate their patterns of adoption. While there are well-established methods in the literature to recognise the heterogeneity of decision makers (see Stringer et al. 2020 for a recent example), adoption pathway analysis can be used to do something similar with technologies. The wide range of agricultural innovations and their possible combinations and adaptations (see Glover et al. 2019) are often assumed to follow the same process of adoption, but this is unlikely to be the case, and adoption pathway analysis can facilitate further empirical research on this topic. In terms of farmer typologies, adoption pathways analysis can be used to explore the definition of new farmer groups, in which typologies are defined according to their adoption patters or how they navigate management decisions over time (Roesch-Mcnally et al. 2018).

\section{Conclusion}

We have illustrated an approach that can be used by adoption researchers and modelers conducting empirical studies to better account for the dynamics of adoption over time as recommended by Pannell et al. (2006), Wilkinson (2011), Brown et al. (2017) and Pannell \& Claassen (2020). We achieved this by defining a series of questions to measure adoption as a dynamic process that could improve the design of cross-sectional surveys. Our approach thus addresses the current imbalance in survey design that puts more emphasis on potential drivers of adoption (i.e. explanatory variables) at the expense of adoption measures (i.e. dependent variables). We therefore make a contribution to the study of adoption by demonstrating how 
to move from measuring adoption as a discrete event in the past (marking the moment when the landowner started using the innovation) to moving that point in time to the present, ascertaining a pattern of use since adoption and projecting future intentions. This approach thus accounts for the dynamic nature of adoption while still using a cross-sectional survey.

\section{Acknowledgements}

We acknowledge the support of AgResearch and Manaaki Whenua in the development of the research underpinning this study and the respondents of the survey. 


\section{References}

Andersson, J. A., \& D’Souza, S. (2014). From adoption claims to understanding farmers and contexts: A literature review of Conservation Agriculture (CA) adoption among smallholder farmers in southern Africa. Agriculture, Ecosystems and Environment, 187, 116-132. https://doi.org/10.1016/j.agee.2013.08.008

Baumgart-Getz, A., Prokopy, L. S., \& Floress, K. (2012). Why farmers adopt best management practice in the United States: A meta-analysis of the adoption literature. Journal of Environmental Management, 96(1), 17-25. https://doi.org/10.1016/j.jenvman.2011.10.006

Bogart, S. (2020). Sankeymatic (Beta). http://sankeymatic.com

Brown, B., Nuberg, I., \& Llewellyn, R. (2017). Stepwise frameworks for understanding the utilisation of conservation agriculture in Africa. Agricultural Systems, 153, 11-22. https://doi.org/10.1016/j.agsy.2017.01.012

Douthwaite, B., Keatinge, J. D. H., \& Park, J. R. (2001). Why promising technologies fail: The neglected role of user innovation during adoption. Research Policy, 30(5), 819-836. https://doi.org/10.1016/Soo48-7333(oo)oo124-4

Douthwaite, B., Kuby, T., Van De Fliert, E., \& Schulz, S. (2003). Impact pathway evaluation: An approach for achieving and attributing impact in complex systems. Agricultural Systems, 78(2), 243-265. https://doi.org/10.1016/So308-521X(03)oo128-8

Eastwood, C., Klerkx, L., \& Nettle, R. (2017). Dynamics and distribution of public and private research and extension roles for technological innovation and diffusion: Case studies of the implementation and adaptation of precision farming technologies. Journal of Rural Studies, 49, 1-12. https://doi.org/10.1016/j.jrurstud.2016.11.008

Feder, G., Just, R. J., \& Zilberman, D. (1985). Adoption of Agricultural Innovations in Developing Countries : A Survey. Economic Development and Cultural Change, 33(2), 255298. https://doi.org/10.14738/abr.63.4221

Glover, D., Sumberg, J., \& Andersson, J. A. (2016). The adoption problem; or why we still understand so little about technological change in African agriculture. Outlook on Agriculture, 45(1), 3-6. https://doi.org/10.5367/oa.2016.0235

Glover, D., Sumberg, J., Ton, G., Andersson, J., \& Badstue, L. (2019). Rethinking technological change in smallholder agriculture. Outlook on Agriculture, 48(3), 169-180. https://doi.org/10.1177/0030727019864978 
Goodwin, P., Meeran, S., \& Dyussekeneva, K. (2014). The challenges of pre-launch forecasting of adoption time series for new durable products. International Journal of Forecasting, 30(4), 1082-1097. https://doi.org/10.1016/j.ijforecast.2014.08.009

Green, K. C., \& Armstrong, J. S. (2007). Structured analogies for forecasting. International Journal of Forecasting, 23(3), 365-376. https://doi.org/10.1016/j.ijforecast.2007.05.005

Hermans, T. D. G., Whitfield, S., Dougill, A. J., \& Thierfelder, C. (2020). Why we should rethink 'adoption' in agricultural innovation: Empirical insights from Malawi. Land Degradation and Development, May, 1-12. https://doi.org/10.1002/ldr.3833

Jabbar, M. A., Beyene, H., Mohamed Saleem, M. A., \& Gebreselassie, S. (1998). Adoption pathways for new agricultural technologies : An approach and an application to vertisol management technology in Ethiopia (No. 23; Socioeconomic and Policy Research, Issue 23).

Knowler, D., \& Bradshaw, B. (2007). Farmers' adoption of conservation agriculture: A review and synthesis of recent research. Food Policy, 32(1), 25-48. https://doi.org/10.1016/j.foodpol.2006.01.003

Kuehne, G., Llewellyn, R., Pannell, D. J., Wilkinson, R., Dolling, P., Ouzman, J., \& Ewing, M. (2017). Predicting farmer uptake of new agricultural practices: A tool for research, extension and policy. Agricultural Systems. https://doi.org/10.1016/j.agsy.2017.06.007

Kuntosch, A., \& König, B. (2018). Linking system perspectives with user perspectives to identify adoption barriers to food security innovations for smallholder farmers - evidence from rural Tanzania. Food Security, 1o(4), 881-896. https://doi.org/10.1007/s12571-0180821-4

Leeuwis, C., \& Aarts, N. (2011). Rethinking communication in innovation processes: Creating space for change in complex systems. The Journal of Agricultural Education and Extension, 17(1), 21-36. https://doi.org/10.1080/1389224X.2011.536344

Liu, T., Bruins, R. J. F., \& Heberling, M. T. (2018). Factors influencing farmers' adoption of best management practices: A review and synthesis. Sustainability (Switzerland), 10(2), 1-27. https://doi.org/10.3390/su10020432

Mason, R. (1962). An ordinal scale for measuring the adoption process. In E. Katz (Ed.), Studies of Innovation and of Communication to the Public: Vol. II (pp. 100-116). Stanford University. https://doi.org/Institute for Communication Research Stanford University Montes de Oca Munguia, O., \& Llewellyn, R. (2020). The adopters versus the technology: 
Which matters more when predicting or explaining adoption? Applied Economic Perspectives and Policy, 42(1), 80-91. https://doi.org/10.1002/aepp.13007

Pannell, D. J., \& Claassen, R. (2020). The roles of adoption and behavior change in agricultural policy. Applied Economic Perspectives and Policy, 42(1), 31-41. https://doi.org/10.1002/aepp.13009

Pannell, D. J., Marshall, G. R., Barr, N., Wilkinson, A., Curtis, F., Vanclay, R., Pannell, R., Barr, R., \& Wilkinson, R. (2006). Understanding and promoting adoption of conservation practices by rural landholders. Australian Journal of Experimental Agriculture, 46(11), 1407-1424. https://doi.org/10.1071/EAo5037

Prokopy, L. S., Floress, K., Arbuckle, J. G., Church, S. P., Eanes, F. R., Gao, Y., Gramig, B. M., Ranjan, P., \& Singh, A. S. (2019). Adoption of agricultural conservation practices in the United States: Evidence from 35 years of quantitative literature. Journal of Soil and Water Conservation, 74(5), 520-534. https://doi.org/10.2489/jswc.74.5·520

Roesch-Mcnally, G. E., Basche, A. D., Arbuckle, J. G., Tyndall, J. C., Miguez, F. E., Bowman, T., \& Clay, R. (2018). The trouble with cover crops: Farmers' experiences with overcoming barriers to adoption. Renewable Agriculture and Food Systems, 33(4), 322-333. https://doi.org/10.1017/S1742170517000096

Sartas, M., Schut, M., Proietti, C., Thiele, G., \& Leeuwis, C. (2020). Scaling readiness : Science and practice of an approach to enhance impact of research for development. Agricultural Systems, 183(June), 1-52. https://doi.org/10.1016/j.agsy.2020.102874

Springer-Heinze, A., Hartwich, F., Simon Henderson, J., Horton, D., \& Minde, I. (2003). Impact pathway analysis: An approach to strengthening the impact orientation of agricultural research. Agricultural Systems, 78(2), 267-285. https://doi.org/10.1016/So3o8521X(03)00129-X

Stahlmann-Brown, P. (2019). Survey of Rural Decision Makers. Manaaki Whenua - Landcare Research. https://doi.org/10.7931/hkeq-ax12

Stringer, L. C., Fraser, E. D. G., Harris, D., Lyon, C., Pereira, L., Ward, C. F. M., \& Simelton, E. (2020). Adaptation and development pathways for different types of farmers. Environmental Science and Policy, 104(October 2019), 174-189. https://doi.org/10.1016/j.envsci.2019.10.007

Tey, Y. S., \& Brindal, M. (2012). Factors influencing the adoption of precision agricultural technologies: A review for policy implications. Precision Agriculture, 13(6), 713-730. 
https://doi.org/10.1007/s11119-012-9273-6

Vanclay, F. M., Russell, A. W., \& Kimber, J. (2013). Enhancing innovation in agriculture at the policy level: The potential contribution of technology assessment. Land Use Policy, 31, 406-411. https://doi.org/10.1016/j.landusepol.2012.08.004

Wauters, E., \& Mathijs, E. (2014). The adoption of farm level soil conservation practices in developed countries: a meta-analytic review. International Journal of Agricultural Resources, Governance and Ecology, 10(1), 78-102.

https://doi.org/10.1504/IJARGE.2014.061058

Weersink, A., \& Fulton, M. (2020). Limits to profit maximization as a guide to behavior change. Applied Economic Perspectives and Policy, 42(1), 67-79. https://doi.org/10.1002/aepp.13004

Wigboldus, S., Klerkx, L., Leeuwis, C., Schut, M., Muilerman, S., \& Jochemsen, H. (2016). Systemic perspectives on scaling agricultural innovations. A review. Agronomy for Sustainable Development, 36(3). https://doi.org/10.1007/s13593-016-0380-z

Wilkinson, R. (2011). The many meanings of adoption. In D. J. Pannell \& F. Vanclay (Eds.), Changing Land Management: Adoption of New Practices by Rural Landholders. CSIRO Publishing. 


\section{Appendix 1}

This appendix contains detailed description of results for the three practices that were not covered in detail in the results section.

\section{A.1. Adoption pathways}

Figures $A_{1}$ to $A_{3}$ show the pattern of adoption for each practice from when the practice became available to farmers to its current level of uptake and use. The placing of the vertical lines in the diagrams are for illustration purposes and are not at scale, but they do indicate different time spans for each stage based on survey responses (e.g. the difference between time from awareness to start using the practice with or without trial). The numerical values for these differences are described in the text explain each figure. The number following each label in the diagrams is the number of respondents following each path, these numbers are also presented as a percentage of total responses).

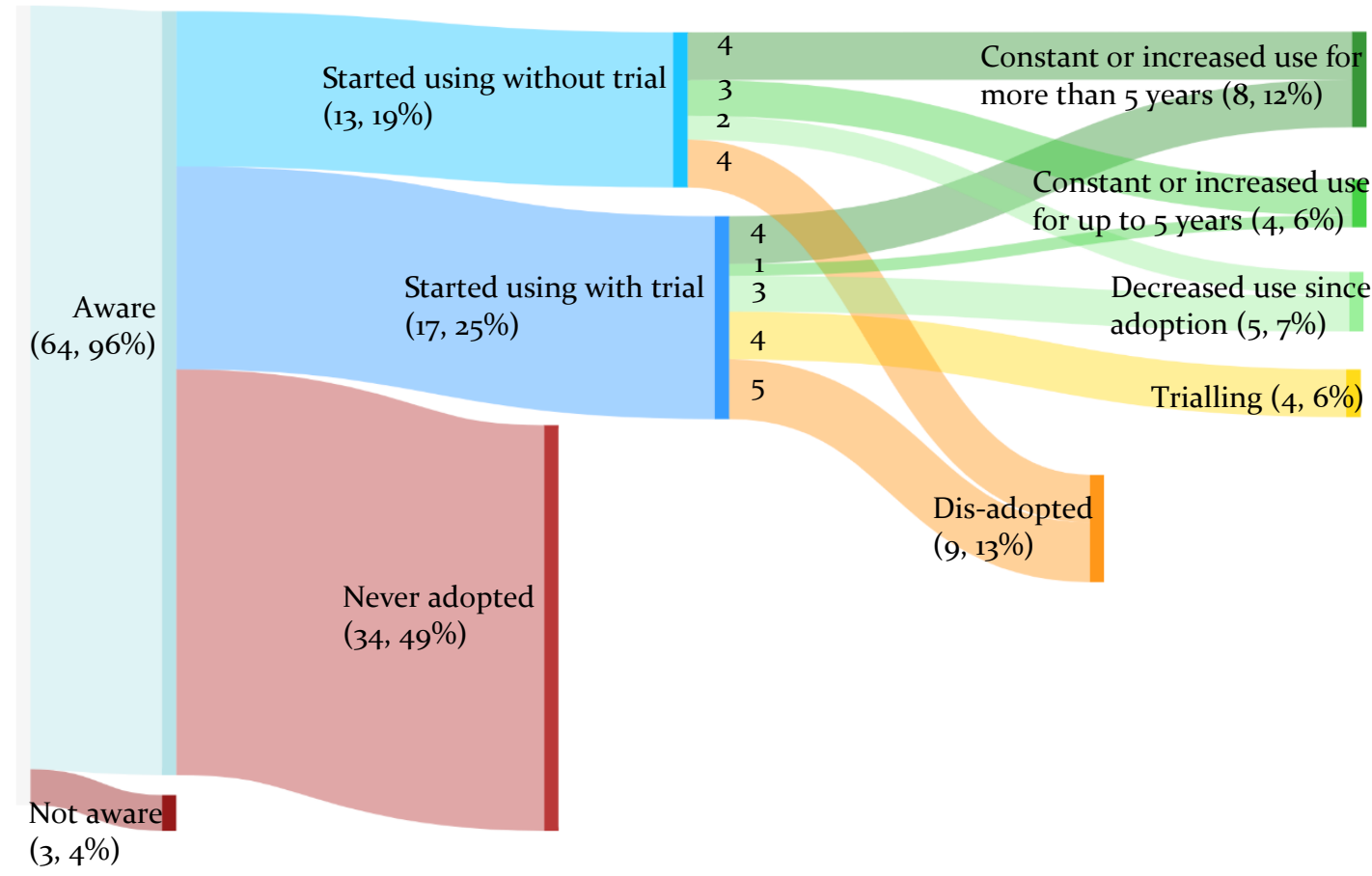

Figure A1. Adoption pathway for the use of pasture management software amongst pastoral farmers in New Zealand.

The diagram illustrates the time from awareness (left-had side) to current use (right hand side). The placing of the vertical lines illustrate different time spans for each stage based on survey responses (e.g. the difference between time from awareness to start using the practice

with or without trial), but they are not at scale. The number following each label is the number of respondents following each path, these numbers are also presented as a percentage of total responses). 
The adoption pathway for the use of pasture management software can be seen in Figure Al. Farmers that adopted pasture management software after identifying a trial period adopted slightly slower than those who didn't (1.1 years). The average timespan from awareness to the time of the survey was 13 years.

If the adoption of pasture management software was measured binarily, the adoption rate would be estimated at $43 \%$. However, the diagram shows that when former adopters are excluded from this calculation, the level of adoption at the time of the survey was $30 \%$. Users reporting using pasture management software consistently or increasingly for more than 5 years accounted for $12 \%$ of all current users, while $6 \%$ of current users have been consistently using it for up to five years at the time of the survey, $7 \%$ of current users have reported a decrease use of the practice and $6 \%$ are in a trial period.

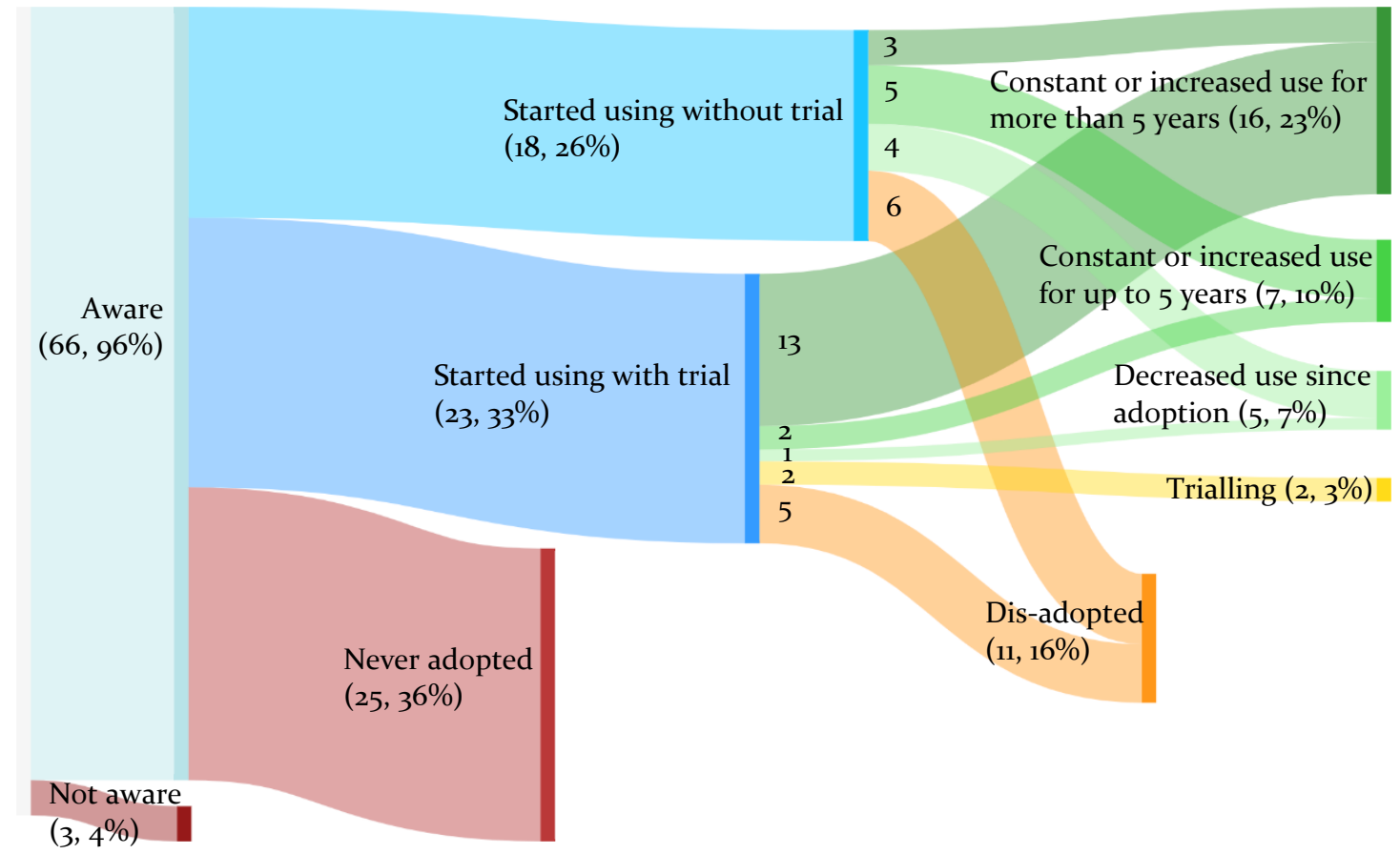

Figure A2 Adoption pathway for the use of Plantain and/or Lucerne for summer grazing amongst pastoral farmers in New Zealand.

The diagram illustrates the time from awareness (left-had side) to current use (right hand side). The placing of the vertical lines illustrate different time spans for each stage based on survey responses (e.g. the difference between time from awareness to start using the practice

with or without trial), but they are not at scale. The number following each label is the number of respondents following each path, these numbers are also presented as a percentage of total responses).

Figure A2 shows the adoption pathway for the use of Plantain and/or Lucerne for summer grazing. Survey results indicated that farmers that adopted this practice after identifying a trial 
period adopted substantially faster than those who didn't (1 years). The average timespan for this practice from awareness to the time of the survey was 14 years.

Binary adoption for this practice was estimated at 59\%. Excluding former adopters this estimate reduced to $43 \%$. Users reporting using Plantain/Lucerne consistently or increasingly for more than 5 years accounted for $23 \%$ of all current users, while $10 \%$ of current users have been consistently using it for up to five years at the time of the survey, $7 \%$ of current users have reported a decrease use of the practice and $3 \%$ are still trialling it.

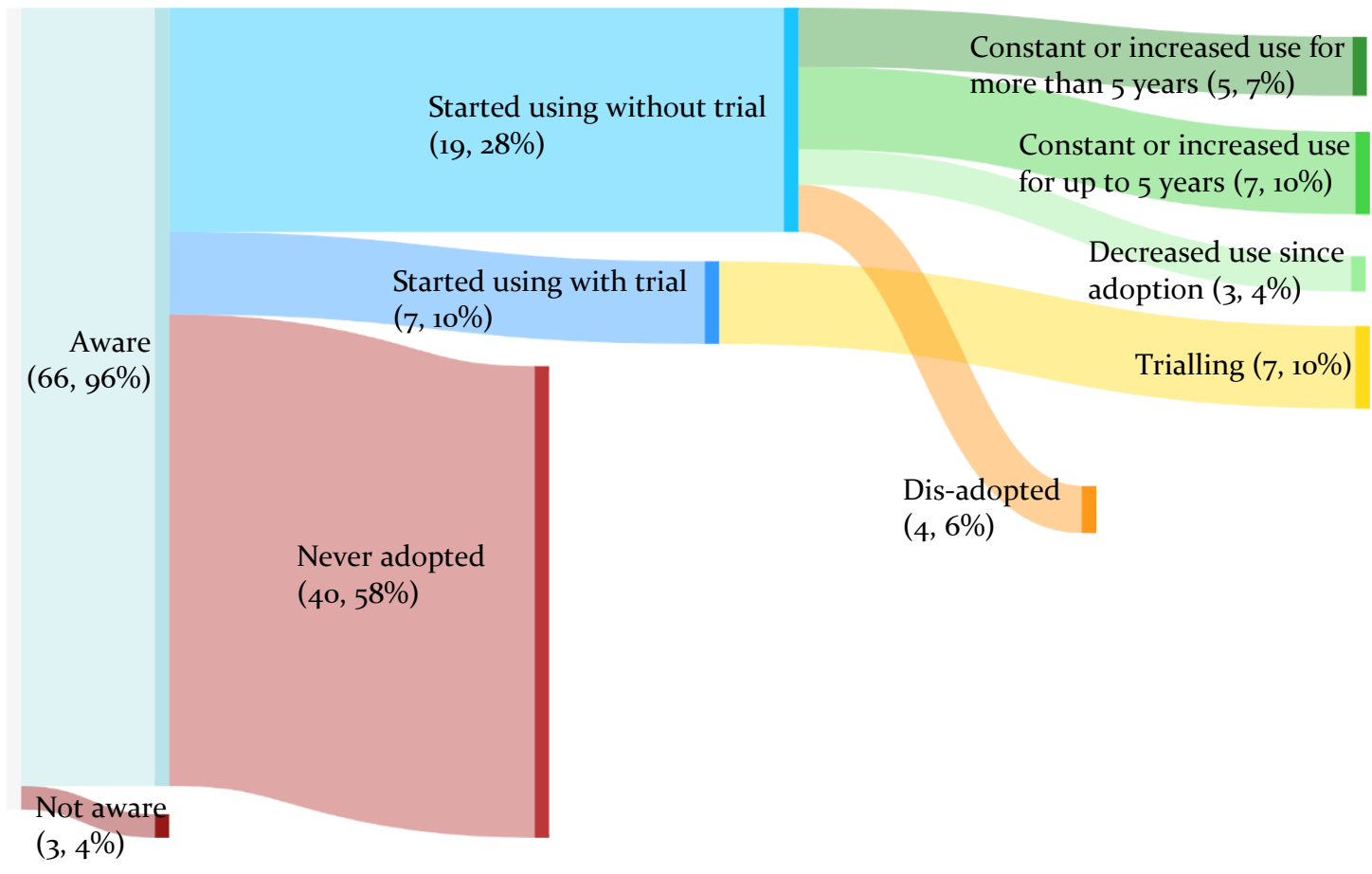

Figure A3 Adoption pathway for the use of use of a formal, audited nutrient management plan amongst pastoral farmers in New Zealand.

The diagram illustrates the time from awareness (left-had side) to current use (right hand side). The placing of the vertical lines illustrate different time spans for each stage based on survey responses (e.g. the difference between time from awareness to start using the practice with or without trial), but they are not at scale. The number following each label is the number of respondents following each path, these numbers are also presented as a percentage of total responses).

The adoption pathway for the use of formal, audited nutrient management plans can be seen in Figure A3. Survey results indicated that farmers that that could identify a trial period for this practice adopted slightly faster than those who didn't ( $1 / 2$ year). The average timespan from awareness to the time of the survey was 8 years. This practice had therefore the shortest time span in relation to the other practices. 
If the adoption of this practice was measured binarily, the adoption rate would be estimated at $38 \%$. However, the diagram shows that when former adopters are excluded from this calculation, the level of adoption at the time of the survey was $32 \%$. Because of the shorter time span of this practice, users reporting using nutrient plans consistently or increasingly for more than 5 years accounted for only $7 \%$ of all current users, while $10 \%$ of current users have been consistently using it for up to five years at the time of the survey, $4 \%$ of current users have reported a decrease use of the practice since adoption and $10 \%$ are still trialling it.

\section{A.2. Future pathways}

Figures $\mathrm{A}_{4}$ to A6 show the current status for each practice at the time of the survey and the future intentions of landowners: Intended changes in levels of use by current users and the reported level of interest in each practice amongst non-adopters and former adopters.

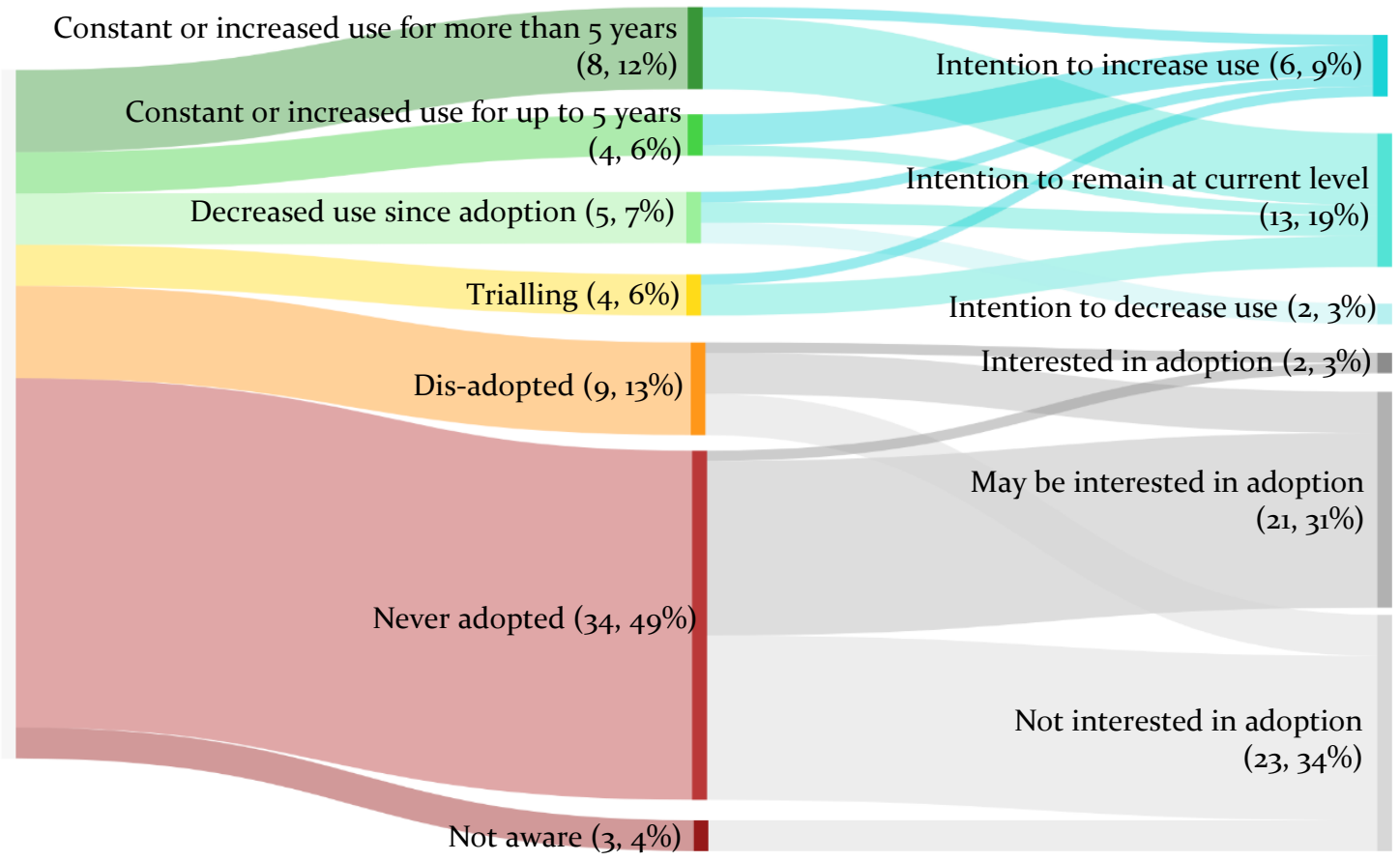

Figure A4 Future pathway for the use of pasture management software amongst pastoral farmers in New Zealand.

Figure $\mathrm{A}_{4}$ shows a split in the intentions regarding changing the extent of the use of pasture management software amongst current users. The majority still intended to use the practice at the current level, but some were considering increasing it. Some current users that have decreased its use over time indicated an intention to further decrease its use. Figure $\mathrm{A}_{4}$ also shows that half of the farmers currently not using the practice were not interested in adopting it in the near future. However, half indicated willingness to consider it. 


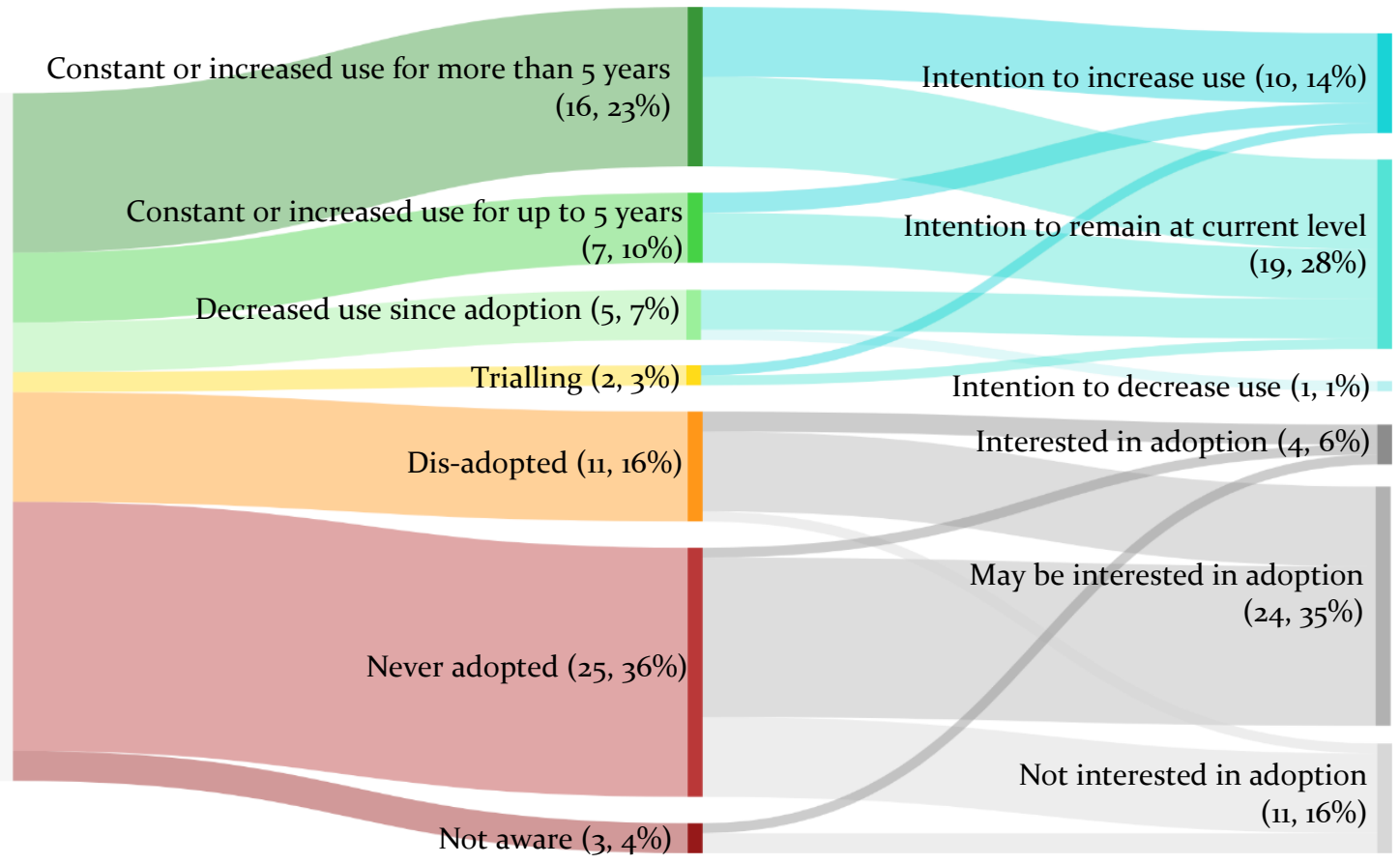

Figure A5 Future pathway for the use of Plantain and/or Lucerne for summer grazing amongst pastoral farmers in New Zealand.

Figure $A_{5}$ shows a very similar pattern of intentions regarding changing the extent of the use of this practice amongst current users as the previous practice. The majority still intend to use Plantain/Lucerne at the current level, but some are considering increasing its use and one user who has been decreasing its use over time intends to further decrease its use. Figure $\mathrm{A}_{5}$ also shows that a majority of farmers currently not using the practice indicated willingness to consider it in the near future, especially former adopters. 


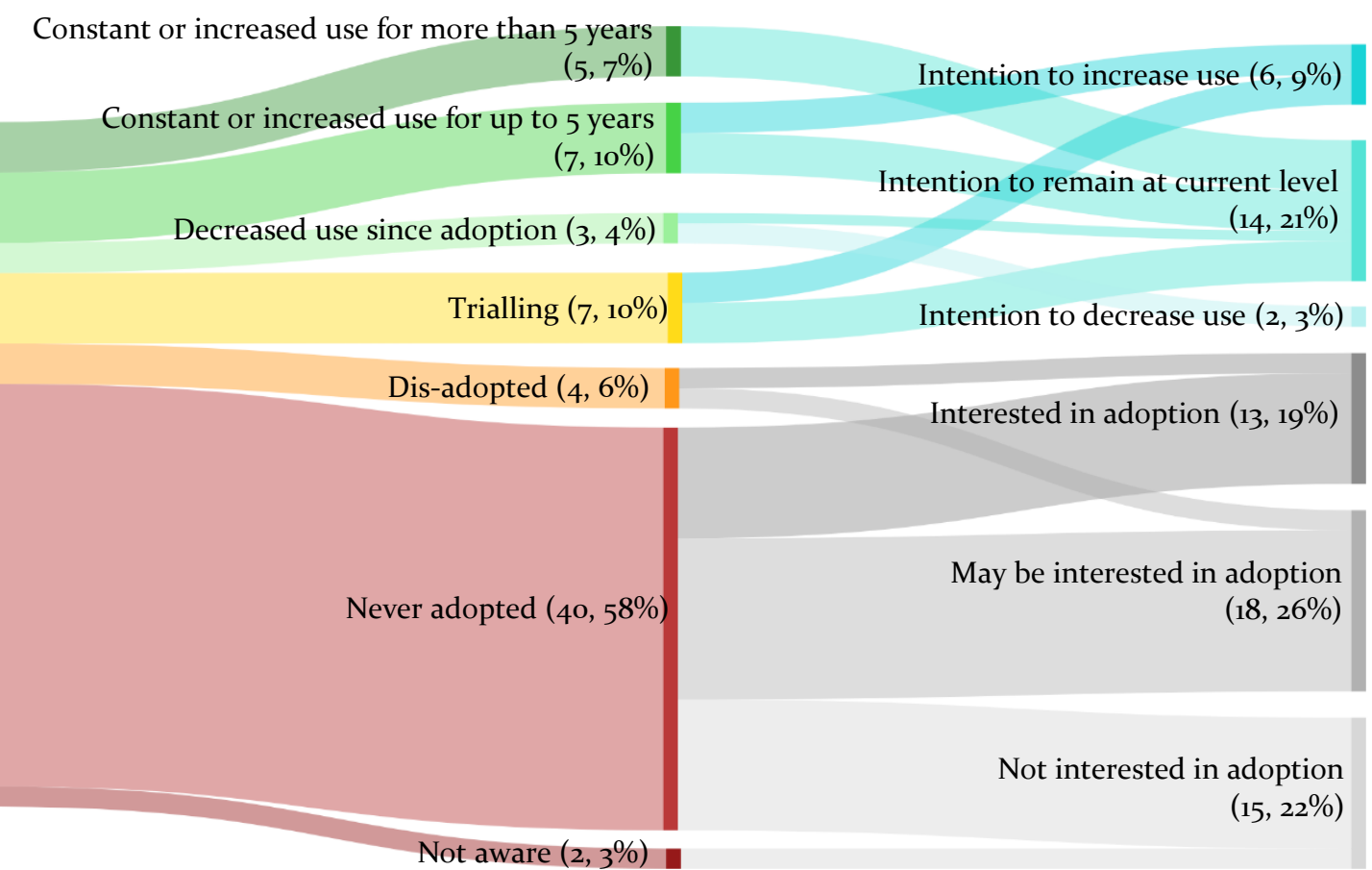

Figure A6 Future pathway for the use of a formal, audited nutrient management plan amongst pastoral farmers in New Zealand.

Figure A6 shows a split in the intentions of current users of management plans. The majority intend to use the nutrient management plans at the current level, with some willing to increase their use and two landowners are planning to further decrease their use. Figure A6 also shows that a majority of farmers currently not using the practice indicated interest in adopting or re-adopting it in the near future. Almost a third of current non-adopters indicated no interest. The level of interest in adopting or re-adopting nutrient management plans in the near future amongst current non-users was the highest in relation to the rest of the practices. 